\title{
ESTUDO QUÍMICO DAS SEMENTES E CASCA DA MADEIRA DE GUAREA TRICHILIOIDES (MELIACEAE).
}

\author{
Esther L.A. WOLTER', Arnaldo F.I. da ROCHA², Wilson WOLTER FILHO', \\ Orlando L. PEREIRA JÚNIOR ${ }^{1}$, Jane Beatriz G. SIQUEIRA ${ }^{1}$, Maria das \\ Graças B. ZOGHBI ${ }^{1}$
}

RESUMO - Da casca da madeira de Guarea trichilioides foram isoladas e identificadas através de métodos espectrométricos as antraquinonas crisofanol e fisciona e das sementes o limonóide 7-desacetoxi-7-hidroxiazadirona. Da fração lipofilica das sementes foram ainda identificados por co-injeçao de padrões, através de cromatografia gasosa os ácidos esteárico, palmítico e linolênico.

Palavras-Chave: Meliaceae, Guarea trichilioides, Limonóides, Antraquinonas, Wiley/NBS.

Chemical Study of Fruits and Steam Bark of Guarea trichilioides (Meliaceae).

ABSTRACT - In this paper we related the identification and isolation of stearic. linolenic and palmitic acids and the isolation and structural determination of the 7-desacetoxy-7hidroxyazadirone present in the hexan extract of the fruits of Guarea trichilioides. From the chloroform extrat of steam bark were isolated and identificated the antraquinones: chrysophanol and physcion.

Key-words: Meliaceae, Guarea trichilioides, Limonoids, Antraquinones, Wiley/NBS.

\section{INTRODUÇÃO}

A familia Meliaceae está incluída na ordem Rutales e possui cerca de 60 gêneros e 1400 espécies. Do ponto de vista químico, caracterizase pela ocorrência predominante de limonóides, incluindo-se ainda, protolimonóides, precurssores biogenéticos dos limonóides (TAYLOR, 1984), flavonóides, isolados da casca da madeira de Soymida febrifuga (BANERJI et al., 1983); cumarinas, isoladas das espécies Ekerbegia senegalensis e Cedrela toona (NAGASAMPAGI et al.. 1975), alcoóis sesquiterpênicos isolados de
Cedrela toona e derivados de cicloartanos, isolados de Guarea trichilioides (BANERJ et al., 1984). As antraquinonas fisciona e crisofanol de ampla distribuição no reino vegetal são freqüentemente encontradas em espécies do gênero Vatairea (FORMIGA et al., 1975). A espécie Guarea trichilioides se encontra distribuída nas Antilhas, Guianas e parte da América do Sul onde é usada na medicina popular como abortiva e anti-sifilítica (LOUREIRO et al., 1968). O gênero Guarea contém cerca de 60 espécies, distribui-se em toda a Amazonia Brasileira e especialmente nos estados do Amazonas e Pará onde

1 Instituto Nacional de Pesquisas da Amazônia, Coordenação de Pesquisas em Produtos Naturais, Caixa Postal 478, 690110-970, Manaus, Amazonas, Brasil.

2 Universidade do Amazonas 
é conhecida popularmente como gitó, canjerana e cedro branco (ANGELY, 1960).

\section{MATERIAL E MÉTODOS}

Um espécimem de Guarea trichilioides foi coletado no Furo do Xiborena, Manaus-Am, identificado pelo Dr. William Rodrigues e registrado no herbário do INPA sob o número 160108 . As sementes e as cascas da madeira após secagem e moagem foram extraidas a frio com hexano e clorofórmio respectivamente. Após eliminação do solvente obteve-se dois extratos: hexânico (sementes) e clorofórmico (casca da madeira). Parte do extrato hexânico foi submetido a processo de saponificação obtendo-se duas frações: saponificada e insaponificada. A fração lipofilica foi submetida à análise através de cromatografia gasosa, utilizando-se cromatógrafo Carlo Erba modelo 3160 com ionização de chama, usando coluna capilar de sílica de 0,25 ìm de SE-54. Hidrogênio foi utilizado como gás de arraste $(33 \mathrm{~cm} / \mathrm{seg}$.), injetandose 2 il no modo "splitless" usando-se uma solução de n-hexano na proporção de $1: 1000$, com a temperatura do forno a $50^{\circ} \mathrm{C}$ e programação de $60^{\circ} \mathrm{C} / \mathrm{min}$. até $230^{\circ} \mathrm{C}$. A identificação das substâncias foi feita por comparação dos cromatogramas da amostra após co-injeção com padrões puros. A fração orgânica foi submetida a fracionamento cromatográfico em coluna, usando-se sílica gel (Merck 7734) como fase fixa, o que permitiu o isolamento de uma substância sólida, cristalina (I).

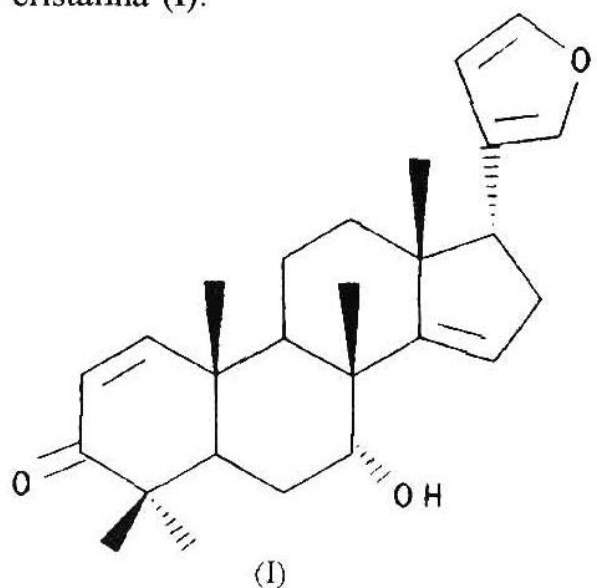

O extrato clorofórmico (casca da madeira) foi submetido a fracionamento cromatográfico em coluna filtrante usando-se sílica gel (Merck 7734) como fase fixa e hexano, benzeno e diclorometano como fase móvel. A fração diclorometânica foi submetida à cromatografia em camada delgada em escala preparativa (CCDP) em sílica (Merck $7734 \mathrm{Pf}_{254}$ ), usando-se éter de petróleo:acetato de etila $(8: 2)$ como eluente o que permitiu o isolamento de duas substâncias (II e III).

\section{RESULTADOS E DISCUSSÃO}

Do extrato hexânico das sementes foram identificados através de $\mathrm{CG}$ os ácidos esteárico, palmítico e linolênico.

A substância I isolada do mesmo extrato foi identificada com base nas informações espectrométricas aliadas as da literatura (PURUSHOTHAMAM $e t$ al., 1985) como sendo a 7-desacetoxi-7hidroxiazadirona. 
As substâncias II e III isoladas da casca da madeira foram identificadas como sendo as antraquinonas Fisciona (II) e Crisofanol (III). Em trabalhos anteriores sobre o estudo químico de espécies da família Meliaceae não existem registros sobre a ocorrência de substâncias antraquinônicas. Entretanto, antraguinóides'são citados na ordem Rutales, mais precisamente na familia Rutaceae, nos gêneros Clausena heptaphyla (casca da madeira) (CHAKRABORTY et al., 1978), Evodia meliaefolia (raízes), Ruta graveolens (raizes) e Zanthoxyloum acanthopodin (raizes) (ROZSA et al., 1977).

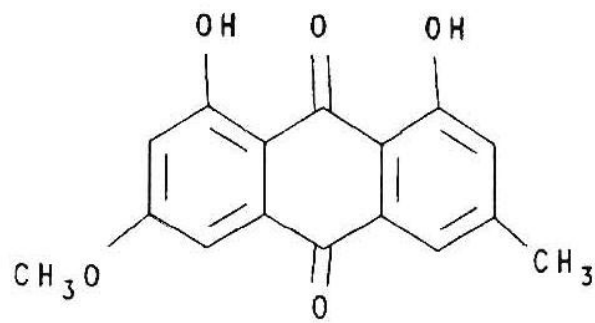

(II)

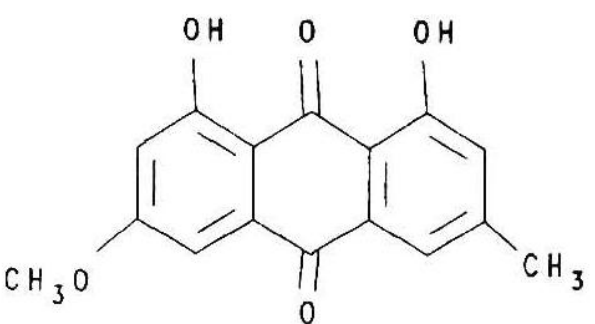

(III)

\section{DADOS ESPECTROSCÓPICOS DAS SUBSTÂNCIAS ISOLADAS.}

\section{7-desacetoxi-7-hidroxiazadirona}

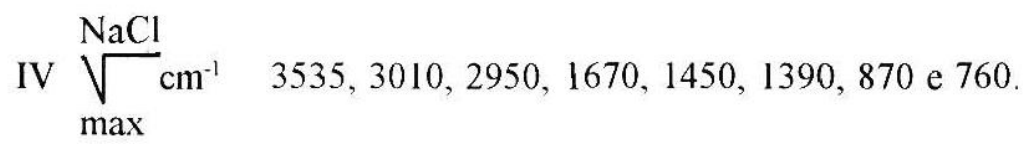

$\mathrm{RMN}^{\prime} \mathrm{H}\left(60 \mathrm{MHz} \mathrm{CDCl}_{3}\right.$, ä) 0,$80 ; 1,06 ; 1,16 ; 3,99(1 \mathrm{H}, \mathrm{t}, \mathrm{J}=$ $3 \mathrm{~Hz}) ; 5,50 ; 5,75(2 \mathrm{H}, \mathrm{d}, \mathrm{J}=10 \mathrm{~Hz})$; 6,$20 ; 7,05(1 \mathrm{H}, \mathrm{d}, \mathrm{J}=10 \mathrm{~Hz})$

$\mathrm{RMN}^{13} \mathrm{C}\left(20 \mathrm{MHz}, \mathrm{CDCl}_{3}\right)$ 204,$8 ; 158,1 ; 152,3 ; 142,6 ; 139,6$; 125,$3 ; 124,3 ; 110,9 ; 71,5 ; 51,6 ; 47,6$ ; 47,2; 44,8; 44,1;40,1;37,2; 36,9 ; 34,$3 ; 32,3 ; 27,5 ; 27,1 ; 24,3 ; 21,5$; 20,$3 ; 18,8$.

EM :M - $394(25 \%) \mathrm{m} / \mathrm{z}(\%)$

$$
\begin{aligned}
& 311(5) ; 299(100) ; 161(18) ; 137 \\
& (13) ; 95(21) ; 91(40) ; 81(100) ; 56
\end{aligned}
$$




\section{Fisciona :}

IV $\sqrt[\max ]{\mathrm{NaCl}}_{\mathrm{cm}^{-1}} 3400,1910,1720,1620,1380$ e 750.

$\mathrm{RMN}^{1} \mathrm{H}\left(200 \mathrm{MHz}, \mathrm{CDCl}_{3}\right.$, ä) 2,$42 ; 3,91 ; 6,85(2 \mathrm{H}, \mathrm{d}, \mathrm{J}=2,7 \mathrm{~Hz})$; 7,$04 ; 7,33 ; 7,58 ; 12,07$ e 12,27 .

\section{Crisofanol:}

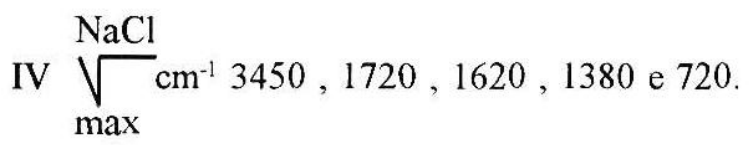

$\mathrm{RMN}^{1} \mathrm{H}\left(200 \mathrm{MHz}, \mathrm{CDCl}_{3}\right.$, ä) 2,$50 ; 7,10(1 \mathrm{H}, \mathrm{d}, \mathrm{J}=1,8 \mathrm{~Hz}), 7,26$; 7,$55 ; 7,65$ e 7,75 .

\section{Bibliografia citada}

ANGELY, J. 1960. Livro dos Gêneros Botânicos Brasileiros. Edições Phyton, Curitiba - PR.

BANERJ, R.; NIGAM, S. K. 1983. Woods constituents of Meliaceae: A Review, Filoterapia, 55, 3.

CHAKHABORTY, D. P., ISLAM, A.; ROY, S. 1978. 2-Methylantraquinone from Clausena heptaphylla. Phytochemistry, 17:2043.

FORMIGA, M. D.; GOTTLIEB, O. R.; MENDES, P. H.; KOKETSU, M.; ALMEIDA, M. E. L.; PEREIRA, M. O. S.; MAGALHÃES, M. T. 1975. Constituentes of Brazilian Leguminosae. Phytochemistry, 14:828.
LOUREIRO, A.; SILVA, M. F. da 1968. Catálogodas madeiras da Amazônia. Vol. 11, 173. INPA.

NAGASAMPAGI, B. A., SIRIMAN, M. C., YANKOV, L.; DEV, S. $1975 . \quad$ Siderin from Cedrela toona. Phytochemistry, $14: 1673$

PURUSHOTHAMAN, K. K., DURAISWAMY, K., CONNOLLY, J. D.; RYCROFT, D. S. 1985. Triterpenoids from Walsura piscidia. Phytochemistry, 24: 2349.

ROZSA, Z. S.; REISCH, J.; LENGYEL, E. 1977. Gravacridondiol and its glucoside from the tissue culture of Ruta gaveolens L. Planta Médica, 32A, 57.

TAYLOR, D. A. H. 1984. The Chemistry of the Limonoids from Meliaceae. Prog. Chem. Org. Nat. Prod., 45:1. 